\title{
Crystallization and melting behavior of nanoclay-containing polypropylene/poly(trimethylene terephthalate) blends
}

\author{
S. H. Jafari ${ }^{1}$, A. Kalati-vahid ${ }^{1}$, H. A. Khonakdar ${ }^{2}$, A. Asadinezhad $^{3}$, U. Wagenknecht ${ }^{4}$, \\ D. Jehnichen ${ }^{4}$ \\ ${ }^{1}$ Department of Polymer, School of Chemical Engineering, College of Engineering, University of Tehran, P.O.Box: \\ 11365-4563, Tehran, Iran \\ ${ }^{2}$ Iran Polymer and Petrochemical Institute, P.O.Box:14965-115, Tehran, Iran \\ ${ }^{3}$ Department of Chemical Engineering, Isfahan University of Technology, P.O.Box: 84156-83111, Isfahan, Iran \\ ${ }^{4}$ Leibniz Institute of Polymer Research Dresden, Hohe Str. 6, D-01069, Dresden, Germany
}

Received 4 May 2011; accepted in revised form 14 September 2011

\begin{abstract}
This contribution concerns preparation and characterization of polypropylene (PP)/poly(trimethylene terephthalate) (PTT) melt-mixed blends in the presence of organically-modified montmorillonite nanoclays and functional compatibilizers. Immiscibility and nanocomposite formation were confirmed via transmission electron microscopy. An intercalated structure was observed by wide angle X-ray diffraction technique. Crystallization, and melting characteristics were studied by differential scanning calorimetry in both isothermal and non-isothermal modes, supplemented by temperature modulated DSC (TMDSC). A concurrent crystallization was found for both polymeric components in the blends. Whereas blending favored PP crystallizability, it interrupted that of PTT. The addition compatibilizers interfered with rate, temperature, and degree of crystallization of PP and PTT. On the contrary, nanoclays incorporation increased crystallizability of each individual component. However, as for blend nanocomposite samples, the way the crystallization behavior changed was established to depend on the type of nanoclay. Based on kinetic analysis, isothermal crystallization nucleation followed athermal mechanism, while that of non-isothermal obeyed thermal mode. Addition of nanoclays shifted nucleation mechanism from athermal to thermal mode.
\end{abstract}

Keywords: nanocomposites, polymer blends, crystallization, polypropylene, poly(trimethylene terephthalate)

\section{Introduction}

The extensive use of polypropylene (PP) in a broad spectrum of applications has fueled a huge interest in conducting research meant for improvement of this common polymer. Aromatic polyesters, thanks to overall superior properties, have found a niche as candidates to foster PP performance via blending and nanocomposite technologies [1, 2]. A major challenge on the way forward is inherent incompatibility of polyester and polyolefin [3, 4]. This has been dealt with to much extent by incorporating compatibilizers such as, maleic anhydride-grafted PP
(PP-g-MAH) [5, 6], ethylene-butyl acrylate-glycidyl methacrylate terpolymer (Elvaloy PTW) [7, 8], and ethylene-glycidyl methacrylate (E-GMA) copolymers $[9,10]$. An alternative, up-to-date approach is to harness clay-based nanofillers [11-17] as well as inorganic nanoscale particles [18] frequently used in polymeric systems originally intended for improving compatibility as well as mechanical properties. An intricate subject in the realm of polymer blends and nanocomposites is crystallization and melting behaviors on which the final properties strongly rely $[19,20]$. The complications indeed, come from

\footnotetext{
${ }^{*}$ Corresponding author, e-mail: shjafari@ut.ac.ir
}

(c) BME-PT 
the critical interactions among the blend components and how the crystallization characteristics are accordingly altered [21]. Poly(trimethylene terephthalate) (PTT), a relatively new member of aromatic polyesters, has been established to possess a combination of properties of two analogous predecessors, poly(ethylene terephthalate) (PET) and poly(butylene terephthalate) (PBT) [22]. Few publications in the literature focus on the thermal properties of PP/PTT blends and nanocomposites which communicate rather contradictory findings in some aspects [23-26]. Xue et al. [23] in a detailed study reported that PTT and PP crystallization rates are expedited by the presence of each other and the acceleration is dependent on the blend ratio. Also PTT showed a fractionated crystallization. PP-g$\mathrm{MAH}$ as a reactive compatibilizer decreased the crystallization temperature of PTT and PP which was more significant for PTT due to the reactivity of maleic anhydride and PTT. It took a longer time to reach a given crystallinity for compatibilized blends compared to the corresponding uncompatibilized ones. Elsewhere, Lin and Cheng [24] in an article on PTT/PP blends reported a complex melting behavior accounted for by recrystallization process. They stated that PP in PTT/PP blends can increase the crystallization rate of PTT and reduce the amount of imperfect PTT crystals. Furthermore, the crystalline structure of PTT in blends remained intact. Wang and Run [25] reported that PTT/PP blends exhibit different crystallization and melting behavior depending on PP-g-MAH content. The results showed that the crystallization rate of PTT component is raised on introduction of PP-g-MAH, even though that of PP component is slowed down. As to PTT/PP nanocomposites with and without PP-gMAH, Upadhyay et al. [26] recently carried out various measurements and observed an intercalated morphology as well as an increase in crystallization temperature of the blend components in presence of nanoclays, however, crystallinity and melting temperature of the components were not affected significantly.

With particular attention to the existing complexities of and rising demands for nano-based multiphase polymer systems, the idea behind the current effort is to shed light on crystallization and melting characteristics of PP/PTT blends in presence of organically modified montmorillonite (Cloisite nan- oclays 20A and 30B), Elvaloy PTW, and PP-gMAH via differential scanning calorimetry (DSC), temperature-modulated DSC (TMDSC), wide-angle $\mathrm{X}$-ray diffraction (WAXS), and transmission electron microscopy (TEM). Cloisite 20A and 30B have been selected on account of their characteristic difference as the former was reported to be considerably more hydrophobic than the latter [27].

\section{Experimental}

\subsection{Materials}

All of the materials used in this work were of commercial grade consumed as received without further treatment. Isotactic PP (Moplen HP501H) with melt flow rate of $2.1 \mathrm{~g} / 10 \mathrm{~min}$ was purchased from Basell Company (Germany). PTT (RTP 4700), with an intrinsic viscosity of $0.901 \mathrm{ml} / \mathrm{g}$, measured at $25^{\circ} \mathrm{C}$ in a 60/40 mixture of phenol and tetrachloroethane, was obtained from RTP Company (USA). Elvaloy PTW, containing $2.4 \mathrm{wt} \%$ GMA, was obtained from DuPont (USA). PP-g-MA (Polybond 3200) was supplied by Chemtura (USA). Cloisite 20A and Cloisite 30B were provided from Southern Clay Products (USA).

\subsection{Samples preparation}

The processing conditions were set based on this fact that it strongly affects nanoclay dispersion [28]. The samples were prepared in an intermeshing twin screw extruder (Berstorff) using a temperature profile of $200-235^{\circ} \mathrm{C}$ at screw speed of $200 \mathrm{rpm}$ in corotating mode. The extrudate was collected in the form of rods in absence of drawing in order not to

Table 1. Compositions and codes of the samples

\begin{tabular}{|l|c|c|c|}
\hline Sample code & $\begin{array}{c}\text { PP/PTT } \\
\text { ratio }\end{array}$ & $\begin{array}{c}\text { Compatibilizer } \\
{[\mathbf{w t} \% \mathbf{]}}\end{array}$ & $\begin{array}{c}\text { Nanoclay } \\
{[\mathbf{w t} \% \mathbf{]}}\end{array}$ \\
\hline PP100 & $100 / 0$ & 0 & 0 \\
\hline PP97CA3 & $100 / 0$ & 0 & 3 Cloisite 20A \\
\hline PP95CA5 & $100 / 0$ & 0 & 5 Cloisite 20A \\
\hline PTT100 & $0 / 100$ & 0 & 0 \\
\hline PTT95CB5 & $0 / 100$ & 0 & 5 Cloisite 30B \\
\hline B100 & $75 / 25$ & 0 & 0 \\
\hline B95E5 & $75 / 25$ & 5 Elvaloy PTW & 0 \\
\hline B95gM5 & $75 / 25$ & 5 PP-g-MAH & 0 \\
\hline B90E10 & $75 / 25$ & 10 Elvaloy PTW & 0 \\
\hline N95CB5 & $75 / 25$ & 0 & 5 Cloisite 30B \\
\hline N95CB2.5CA2.5 & $75 / 25$ & 0 & $\begin{array}{c}2.5 \text { Cloisite 20A + } \\
\text { 2.5 Cloisite 30B }\end{array}$ \\
\hline N90E5CB5 & $75 / 25$ & 5 Elvaloy PTW & 5 Cloisite 30B \\
\hline N85E10CB5 & $75 / 25$ & 10 Elvaloy PTW & 5 Cloisite 30B \\
\hline
\end{tabular}


assume orientation. A constant PP/PTT weight ratio, $75 / 25$, was used with various contents of the compatibilizers and nanoclays. All of the components were introduced to the extruder in a single step. The formulation of the samples is presented in Table 1 .

\subsection{Characterization}

\subsubsection{WAXS}

Wide angle X-ray diffraction (WAXS) analysis was performed on X-ray diffractometer P4 with area detection system GADDS (Bruker, Germany), operating at $40 \mathrm{kV}$ and $30 \mathrm{~mA}$ using $\mathrm{Cu} \mathrm{K}_{\alpha}$ radiation $(\lambda=0.154 \mathrm{~nm})$. The samples were investigated in transmission with primary beam normal to extrusion direction. The scanning was carried out in $2 \theta$ range between 1.8 and $40.5^{\circ}$.

\subsubsection{DSC}

Thermal behavior was examined on Q2000 DSC (TA Instruments USA), with samples of about $5 \mathrm{mg}$ sealed in aluminum pans under nitrogen atmosphere. The samples were first heated from 25 to $250^{\circ} \mathrm{C}$ at $10^{\circ} \mathrm{C} / \mathrm{min}$, kept at $250^{\circ} \mathrm{C}$ for $2 \mathrm{~min}$ to erase the thermal history. To study non-isothermal behavior, cooling was executed down to $25^{\circ} \mathrm{C}$ at the rate of $10^{\circ} \mathrm{C} / \mathrm{min}$. The samples were finally heated back to $250^{\circ} \mathrm{C}$ at the same rate to study the subsequent melting behavior. Isothermal crystallization was performed stepwise at different sets of temperatures to determine the optimal one where the highest crystallization rate for each component was reached. The samples were accordingly cooled from 250 to $170^{\circ} \mathrm{C}$ (optimal isothermal crystallization temperature for PTT), held for 10 min to examine PTT component crystallization, and then prompt cooling continued to $120^{\circ} \mathrm{C}$ (optimal isothermal crystallization temperature for PP), kept for 30 min to examine PP crystallization. Cooling was then performed back to $25^{\circ} \mathrm{C}$ at the rate of $10^{\circ} \mathrm{C} / \mathrm{min}$ and subsequent melting was done at equal rate to $250^{\circ} \mathrm{C}$. Furthermore, crystallization degree was estimated based on the Equation (1):

$$
X_{\mathrm{c}}=\frac{\Delta H_{\mathrm{m}}}{\omega_{\mathrm{f}} \cdot \Delta H_{\mathrm{m}}^{0}} \cdot 100
$$

where $\Delta H_{\mathrm{m}}$ is the measured melting enthalpy and $\Delta H_{\mathrm{m}}^{0}$ is melting enthalpy of $100 \%$ crystalline sample. $\omega_{\mathrm{f}}$ denotes weight percentage. For neat PTT, $\Delta H_{\mathrm{m}}^{0}=$ $145.5 \mathrm{~J} / \mathrm{g}$ [22] and for neat PP, $\Delta H_{\mathrm{m}}^{0}=207.0 \mathrm{~J} / \mathrm{g}$ [29].

\subsubsection{TMDSC}

TMDSC (Mettler Toledo DSC, Switzerland) was managed to investigate the complex melting phenomena on $6 \mathrm{mg}$ samples sealed in aluminum pans. The specimen was heated from 25 to $250^{\circ} \mathrm{C}$ at $10^{\circ} \mathrm{C} / \mathrm{min}$ and kept $2 \mathrm{~min}$ at $250^{\circ} \mathrm{C}$, subsequently cooled down to $25^{\circ} \mathrm{C}$ at the rate of $10^{\circ} \mathrm{C} / \mathrm{min}$ and heated to $100 \mathrm{C}$. The final heating was carried out from 100 to $240^{\circ} \mathrm{C}$ to observe cold crystallization at amplitude of $1^{\circ}$ and period of $60 \mathrm{sec}$.

\subsubsection{TEM}

The extruded samples were ultramicrotomed down to $80 \mathrm{~nm}$ thickness under cryogenic conditions at $-120^{\circ} \mathrm{C}$ via EM UC/FC6 ultramicrotome (Leica, Germany) equipped with a diamond knife. TEM images were then recorded using LEO 910 TEM (Carl Zeiss, Germany) at an acceleration voltage of $120 \mathrm{kV}$.

\section{Results and discussion \\ 3.1. Morphology}

TEM morphological images of three representative samples are given in Figure 1. As it is evident from Figure 1a, which corresponds to sample N95CB5, PTT droplets are dispersed within PP matrix. Exfoliated Cloisite 30B nanoparticles are distributed in PTT phase as well as blend interphase confirming nanocomposite formation. The higher tendency of Cloisite 30B to PTT has also been reported elsewhere [26] which is principally due to their hydrophilic affinity. On introduction of $2.5 \mathrm{wt} \%$ Cloisite 20A and $2.5 \mathrm{wt} \%$ Cloisite $30 \mathrm{~B}$ to PP/PTT blend (Figure $1 \mathrm{~b}$ ), nanoclay content at the interphase rises significantly to the detriment of that inside PTT droplets which reveals the tendency of Cloisite 20A to reside at the interfacial phase because of its hydrophobic nature. Depending on the material, Cloisite 20A locates selectively in the phase with which it has more affinity [30]. The selective localization of nanoclay is also predictable from surface free energy values (pertinent data not shown). Furthermore, the presence of Cloisite 20A led to an increase in PTT droplets size and aspect ratio seemingly on account of coalescence. According to Figure 1c, addition of the compatibilizer, Elvaloy PTW, as much as $5 \mathrm{wt} \%$ to $\mathrm{N} 95 \mathrm{CB} 5$ gives rise to significant alterations in morphology, viz., an increased PTT dispersion due to reduced interfacial tension 

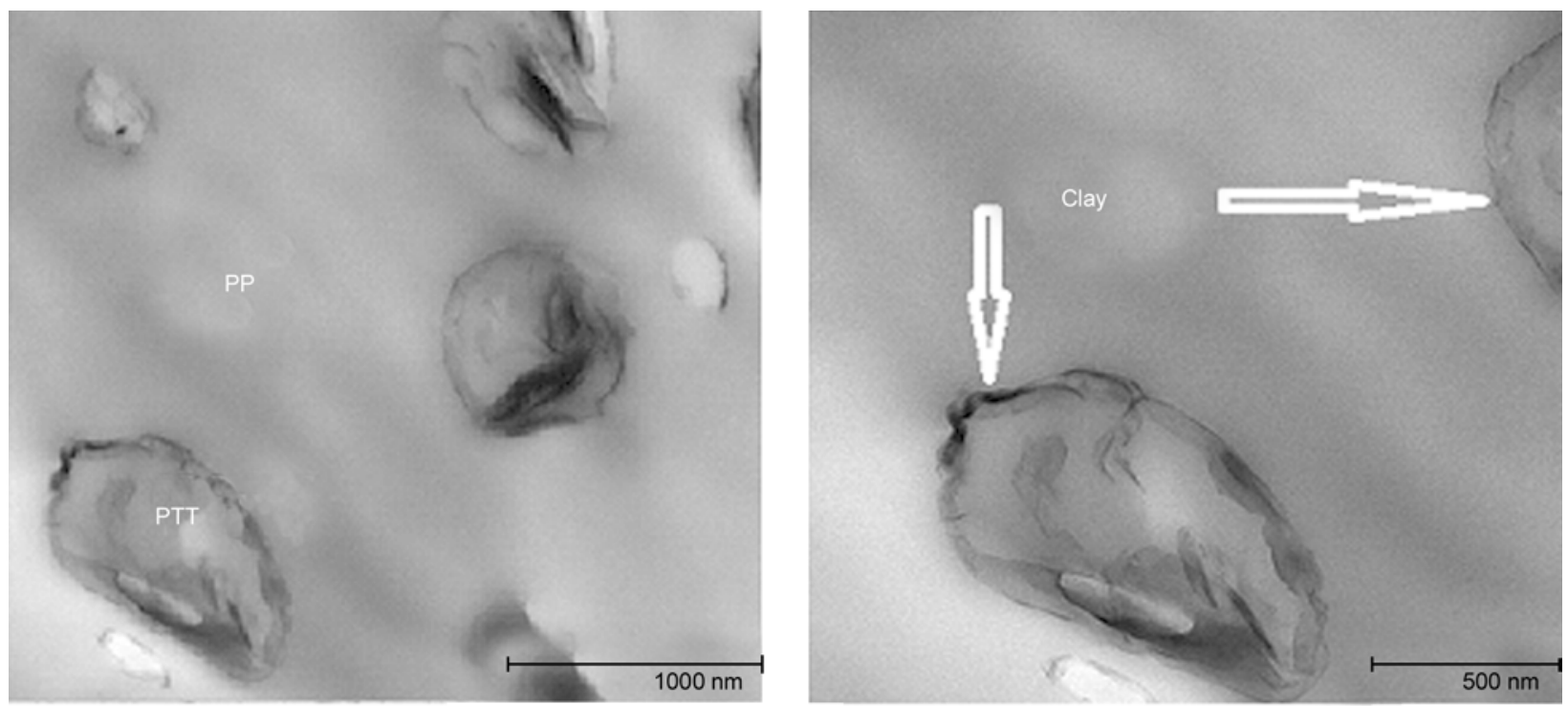

a)
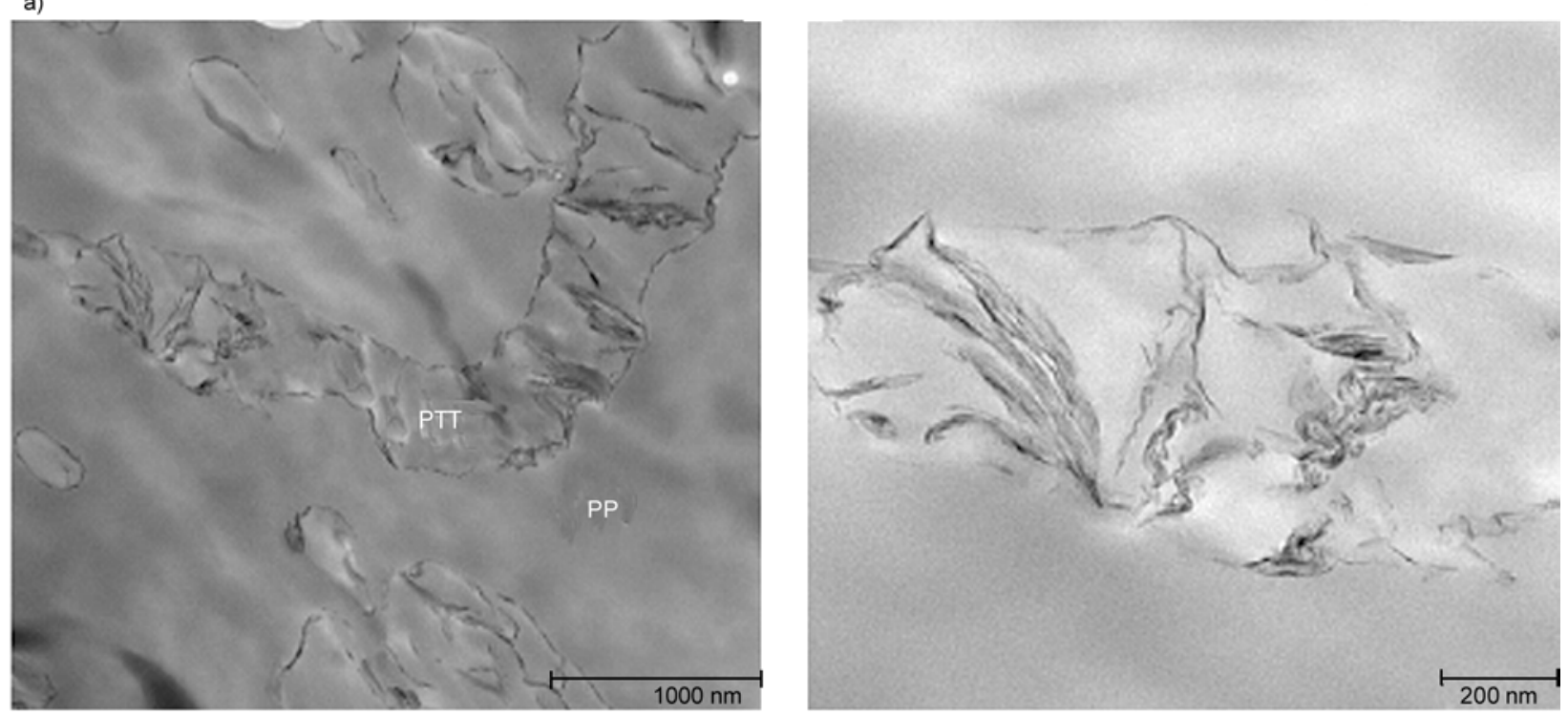

b)

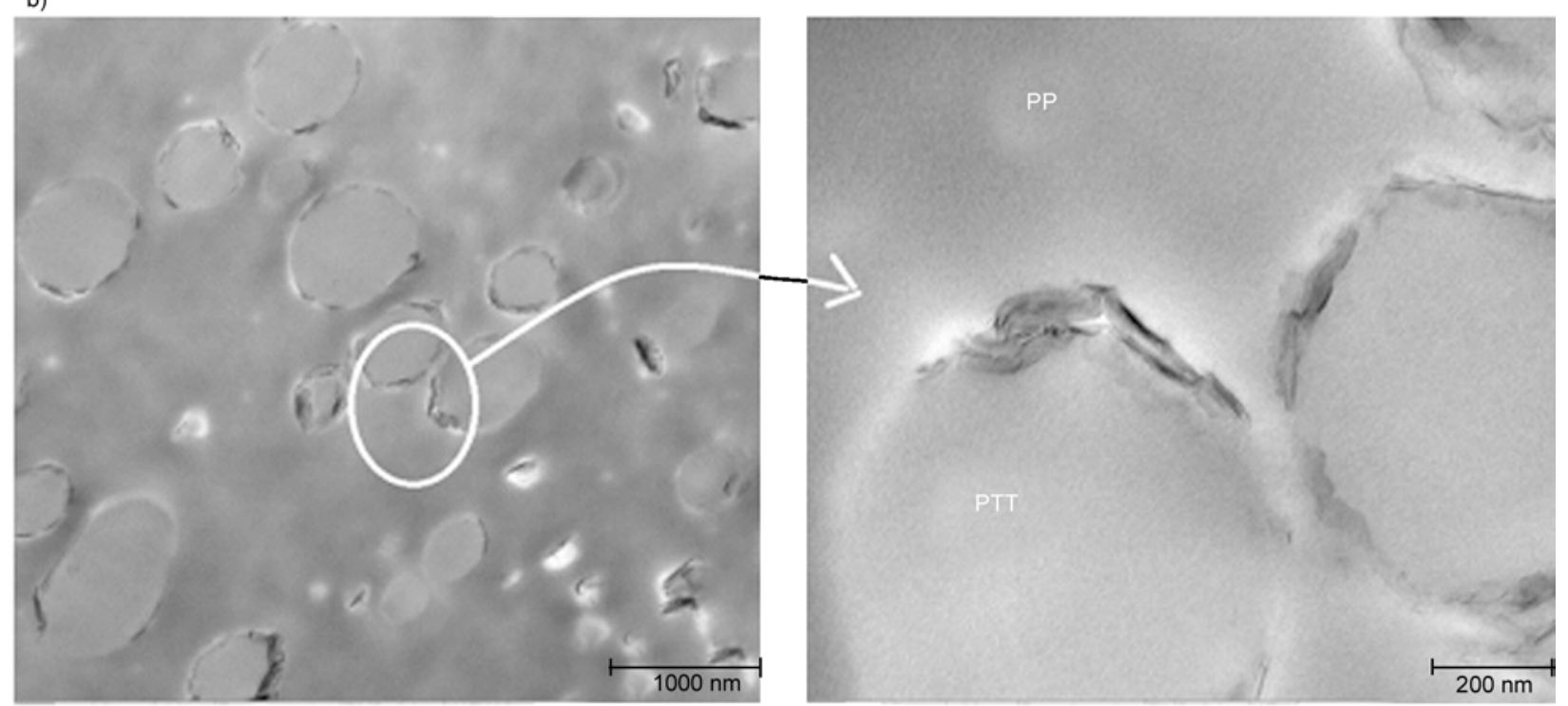

c)

Figure 1. TEM morphological images of different samples: (a) N95CB5, (b) N95CB2.5CA2.5, (c) N90E5CB5 
and coalescence, an enlarged gallery space of clay layers, and a higher amount of nanoclays lying at the interphase rather than within PTT phase domain. The significant difference compared to N95CB5 sample refers to the formation of a compatibilizerrich phase which encompasses a considerable amount of nanoclay due to their affinity. This leads to a reduction of nanoclay presence at the interphase as well as inside PP droplets.

\subsection{X-ray crystallography}

The WAXS patterns from different samples along with pure nanoclays are presented in Figure 2. Over low-scattering-angle range (Figure 2a), the observed peaks in the given patterns correspond to (001) crystalline plane of nanoclays preserved when compounded with polymeric constituents. This is indicative of an intercalated morphology formation being in agreement with Upadhyay et al. [26]. Nanoclays interlayer distance values estimated based on Bragg's law [21] are also embedded in the graph. Data suggests weak interactions between PP chains and Cloisite 20A galleries since the interlayer distance remains nearly unchanged upon blending with PP, while an opposite trend is seen between PTT and Cloisite 30B moieties corroborating the TEM findings. Furthermore, the presence of Cloisite 30B contributes to intercalation by raising the gallery spacing in blend nanocomposite samples implying the facilitated insertion of polymer chains within the interlayer space in virtue of polymer-nanoclay affinity [31].

Based on the patterns shown in Figure 2b, PP $\alpha$ crystalline form is discernible by the signals assigned to (110), (040), (130), (111), (131), and (041) planes. Neat PTT samples gives no characteristic

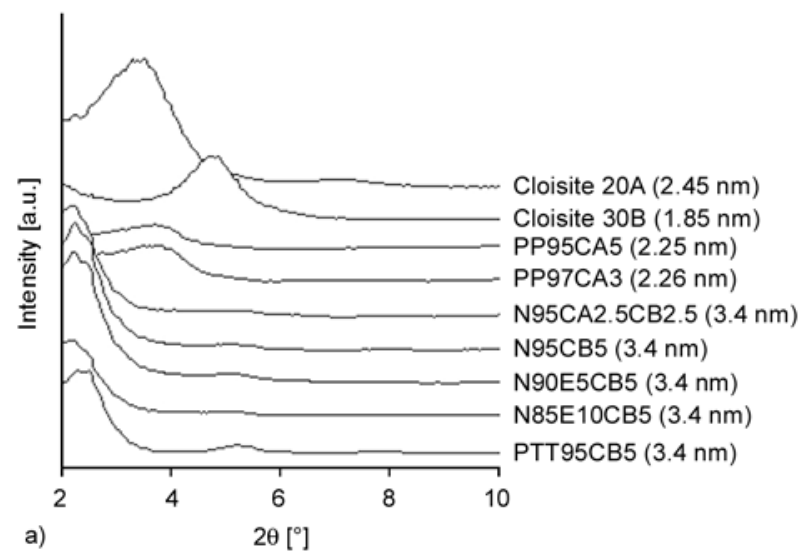

peaks remaining amorphous under imposed processing conditions. Introduction of the compatibilizer and nanoclays into PP/PTT blends has no sensible effect on PP crystalline size similar to what is reported by Lin and Cheng [24]. This is learned from the data calculated for (040) crystal plane in accordance with the Scherrer equation [32] and demonstrated graphically in Figure 3a.

According to the Scherrer equation, the crystal size $(L)$ is given by Equation (2):

$L=\frac{0.9 \cdot \lambda}{\beta \cdot \cos \theta}$

where $\lambda$ denotes wavelength, $\theta$ is scattring angle, and $\beta$ is full width at half maximum. Also, the repsective crystalline percentage $(X)$ is calculated from Equation (3):

$$
X_{040}=\frac{S_{040}}{S_{040}+S_{110}+S_{130}+S_{111}+S_{041}}
$$

In which $S$ refers to area under each scattering peak. Nonetheless, an overall advantageous impact of blending as well as nanoclays incorporation on crystallinity values is found (Figure 3a) obtained based on Zipper equation [33] which may be attributed to the nucleating effects and dispersed phase domain size. Zipper equation gives orientation parameters of (040) crystal plane, $A_{110}$ (Equation (4)), and (110) crystal plane, C (Equation (5)), in terms of signals intensity values $(I)$ :

$$
\begin{aligned}
& A_{110}=\frac{I_{110}}{I_{110}+I_{111}+I_{\overline{131+041}}} \\
& C=\frac{I_{040}}{I_{110}+I_{040}+I_{130}}
\end{aligned}
$$

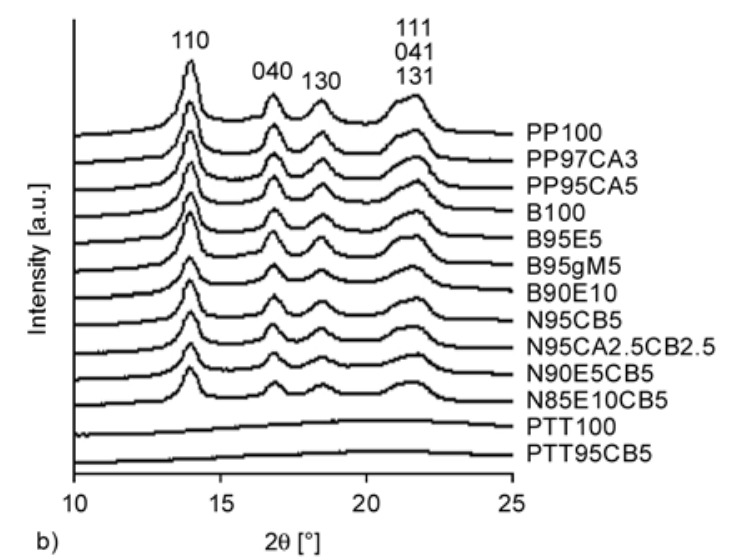

Figure 2. WAXS patterns of different samples: (a) low scattering angle range (b) medium scattering angle range 

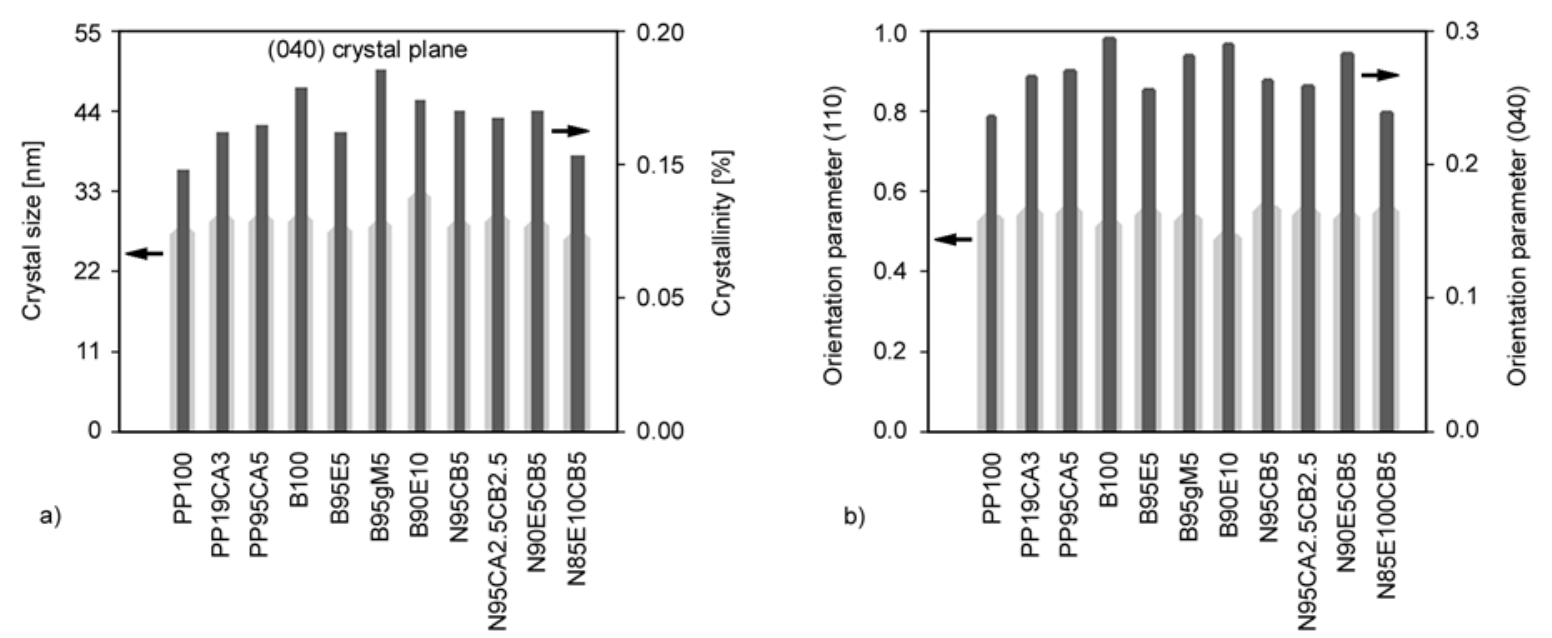

Figure 3. Crystallographic parameters estimated for different samples: (a) crystalline size and percentage, (b) orientation indices of crystal planes

$A_{110}$ and $C$ indices are presented in Figure $3 \mathrm{~b}$. It is deduced such that under processing conditions maintained for samples preparation, orientation index of (110) direction is not influenced while that of (040) is favored by blending and nanocomposite formation.

\subsection{Crystallization and melting}

DSC thermograms of the samples undergone the isothermal crystallization process together with the corresponding heating scan are given in Figure 4 and 5, respectively. A complex melting behavior is observed for neat PP (PP100) arising from melting of crystals with different thermal stability [34]. Moreover, a cold crystallization phenomenon for pure PTT (PTT100) is noticed stemmed from chains reorganization [35]. Both phenomena vanish in heating scan of PP/PTT blend sample (B100), which shows a single crystallization peak in very close proximity to PP exothermic signal. A cursory examination of Figure 4 curves may suggest that PTT remains amorphous, although based on Figure 5, two distinct melting peaks emerge for B100 implying the crystallization of both components. The melting endotherm due to PTT is raised either as a result of melt or cold crystallization. The occurrence of the latter is excluded after a survey into the obtained TMDSC thermograms (Figure 6). Since both reversing and non-reversing heat flow curves possess resembling endotherms, it is understood that no thermally-induced crystallization associated with PTT chains reorganization happens. Therefore, PTT and PP crystallize under cooling simultaneously giv-

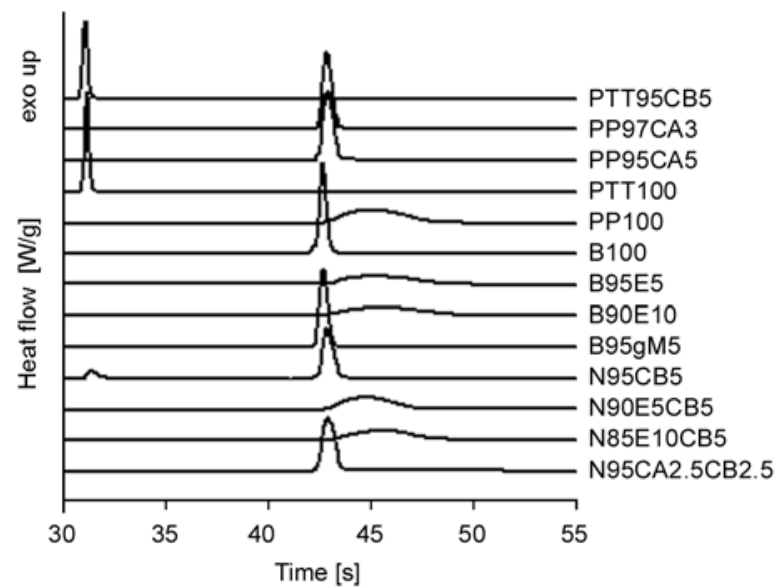

Figure 4. DSC cooling thermograms of the samples crystallized isothermally at certain temperatures

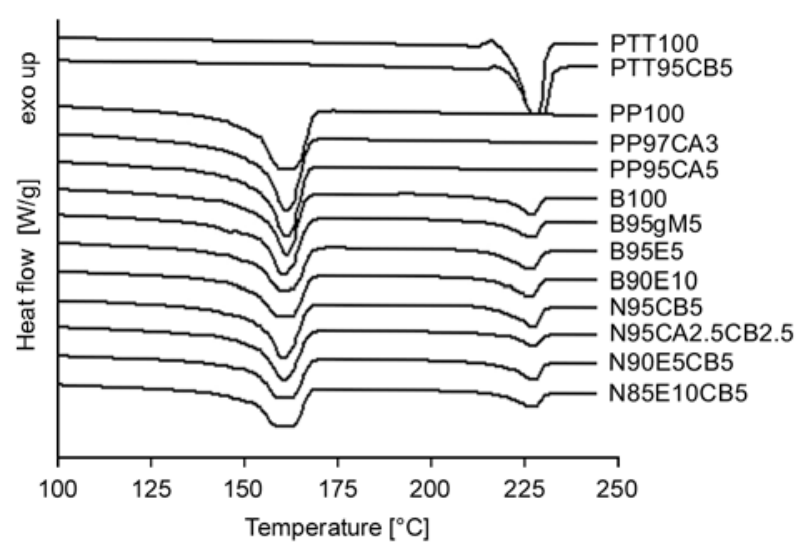

Figure 5. DSC melting thermograms of the isothermallycrystallized samples

ing rise to a concurrent crystallization which normally occurs when the crystallization temperature ranges coincide provided the crystallizability of the blend components is similar [3]. To get further insight into the isothermal crystallization and melting behav- 
Table 2. Isothermal crystallization and the respective melting data of the samples

\begin{tabular}{|c|c|c|c|c|c|c|c|c|}
\hline \multirow{2}{*}{ Sample } & \multicolumn{4}{|c|}{ PP component } & \multicolumn{4}{|c|}{ PTT component } \\
\hline & $\Delta \mathbf{H}_{\mathbf{c}^{(1)}[\mathrm{J} / \mathrm{g}]}$ & $\mathbf{T}_{\mathrm{m}}^{(2)}\left[{ }^{\circ} \mathrm{C}\right]$ & $\Delta \mathbf{H}_{\mathrm{m}}^{(3)}[\mathrm{J} / \mathrm{g}]$ & $\mathbf{X}^{(4)}[\%]$ & $\Delta \mathbf{H}_{\mathbf{c}}[\mathbf{J} / \mathbf{g}]$ & $\mathbf{T}_{\mathrm{m}}\left[{ }^{\circ} \mathbf{C}\right]$ & $\Delta \mathbf{H}_{\mathrm{m}}[\mathbf{J} / \mathbf{g}]$ & $\mathbf{X}[\%]$ \\
\hline PP100 & 84.0 & 161.0 & 84.0 & 40.5 & $\ldots$ & $\ldots$ & $\ldots$ & $\ldots$ \\
\hline PP97CA3 & 85.8 & 161.3 & 85.8 & 42.7 & $\ldots$ & $\ldots$ & $\ldots$ & $\ldots$ \\
\hline PP95CA5 & 85.0 & 160.8 & 85.0 & 43.2 & $\ldots$ & $\ldots$ & $\ldots$ & $\ldots$ \\
\hline PTT100 & $\ldots$ & $\ldots$ & $\ldots$ & $\ldots$ & 50.7 & 227.5 & 50.7 & 35.1 \\
\hline PTT95CB5 & $\ldots$ & $\ldots$ & $\ldots$ & $\ldots$ & 49.5 & 228.6 & 49.5 & 34.7 \\
\hline B100 & 77.0 & 161.0 & 65.0 & 41.9 & $\ldots$ & 227.3 & 12.0 & 33.0 \\
\hline B95gM5 & 76.2 & 160.8 & 66.0 & 44.7 & $\ldots$ & 227.0 & 10.5 & 30.4 \\
\hline B95E5 & 58.0 & 160.5 & 47.5 & 32.2 & $\ldots$ & 226.9 & 10.1 & 28.9 \\
\hline B90E10 & 56.0 & 160.3 & 46.0 & 32.9 & $\ldots$ & 227.5 & 10.0 & 30.5 \\
\hline N95CB5 & 65.1 & 161.0 & 62.0 & 42.0 & 8.9 & 227.7 & 12.0 & 34.7 \\
\hline N95CB2.5CA2.5 & 64.5 & 161.8 & 58.5 & 39.6 & $\ldots$ & 227.9 & 6.0 & 17.3 \\
\hline N90E5CB5 & 54.8 & 159.8 & 45.5 & 32.2 & $\ldots$ & 228.0 & 9.5 & 29.6 \\
\hline N85E10CB5 & 53.9 & 160.1 & 44.0 & 33.5 & $\ldots$ & 228.4 & 10.0 & 30.7 \\
\hline
\end{tabular}

${ }^{(1)}$ Crystallization enthalpy

${ }^{(2)}$ Melting temperature

${ }^{(3)}$ Melting enthalpy

${ }^{(4)}$ Crystallinity

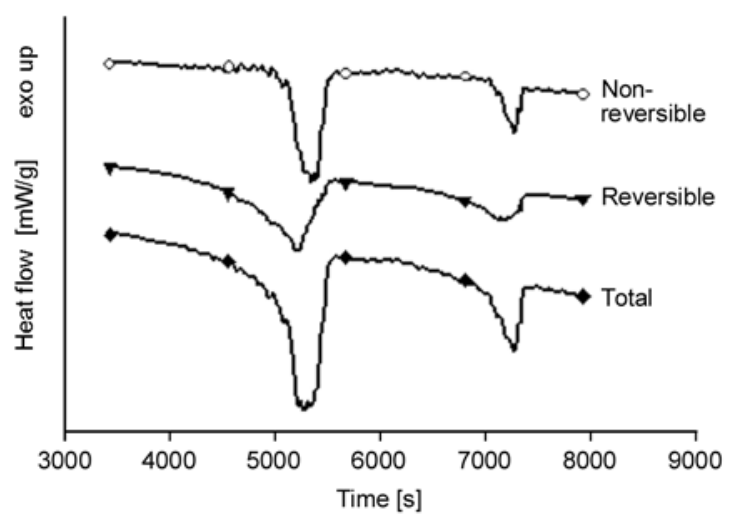

Figure 6. TMDSC curves of B100 sample obtained during heating scan

ior, Table 2 is given embracing numerical data. It is inferred that blending leads to a decrease in crystallization rate and degree of PTT component while the opposite is found for PP. This can be explained based on the favorable role of PTT crystallites for PP nucleation stage, while PTT crystallization is hindered by PP phase being in molten state when PTT is about to crystallize. Similar conclusion has also been reported on PET nucleating role on PP crystallization in PP/PET blend [36].

Non-isothermal crystallization and melting behavior of the samples are respectively demonstrated in Figures 7 and 8 . The cold crystallization of PTT100 again appears, while the complex melting of PP100 disappears. Blending PTT with PP correspondingly results in a decrease in PTT crystallization temperature and an increase in that of PP, as numerically displayed in Table 3. Heating scan of the non-

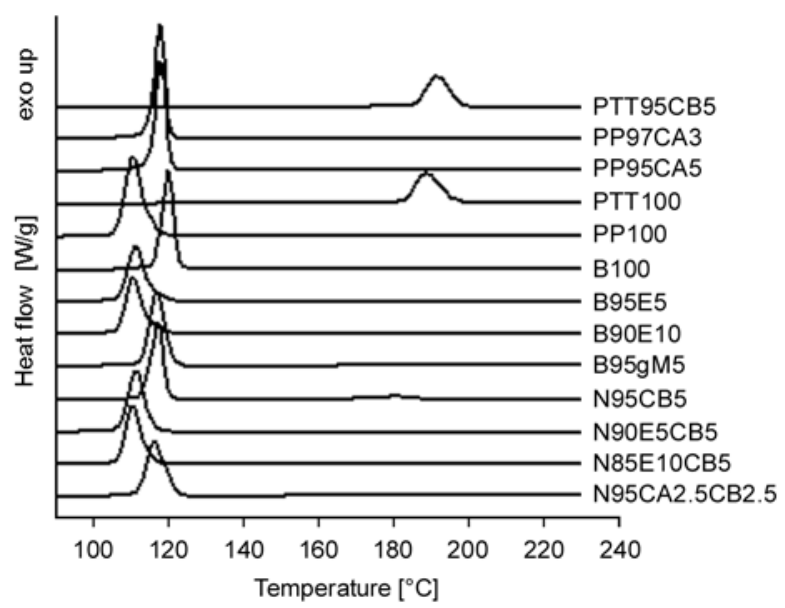

Figure 7. DSC cooling thermograms of the samples crystallized non-isothermally

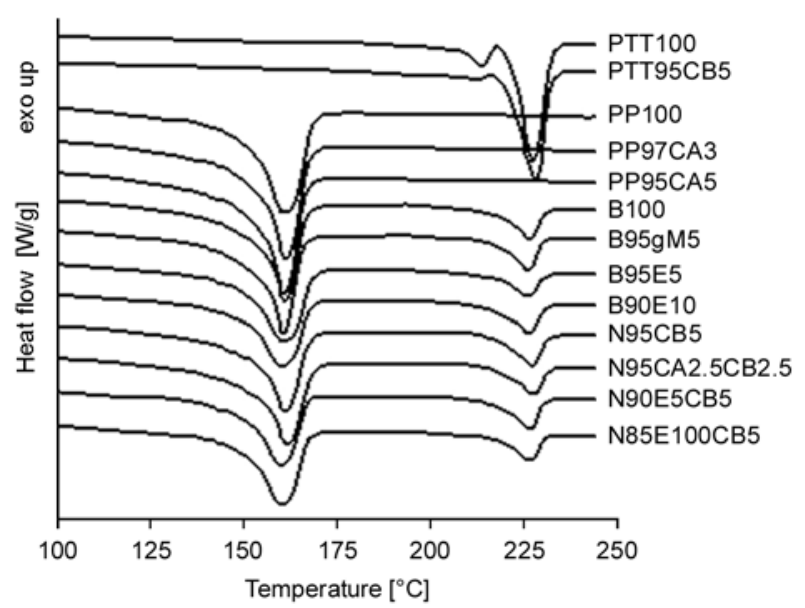

Figure 8. DSC melting thermograms of the non-isothermally-crystallized samples

isothermally crystallized blend (B100) reveals neither complex melting behavior nor recrystallization 
Table 3. Non-isothermal crystallization and the respective melting data of the samples

\begin{tabular}{|l|c|c|c|c|c|c|c|c|}
\hline \multirow{2}{*}{\multicolumn{1}{c|}{ Sample }} & \multicolumn{9}{|c|}{ PP component } & \multicolumn{5}{c|}{ PTT component } \\
\cline { 2 - 11 } & $\mathbf{\Delta}_{\mathbf{c}}[\mathbf{J} / \mathbf{g}]$ & $\mathbf{T}_{\mathbf{m}}\left[{ }^{\circ} \mathbf{C}\right]$ & $\Delta_{\mathbf{H}_{\mathbf{m}}[\mathbf{J} / \mathbf{g}]}$ & $\mathbf{X}[\mathbf{\%}]$ & $\boldsymbol{\Delta}_{\mathbf{c}}[\mathbf{J} / \mathbf{g}]$ & $\mathbf{T}_{\mathbf{m}}\left[{ }^{\circ} \mathbf{C}\right]$ & $\Delta \mathbf{H}_{\mathbf{m}}[\mathbf{J} / \mathbf{g}]$ & $\mathbf{X}[\mathbf{\%}]$ \\
\hline PP100 & 86.7 & 160.7 & 86.7 & 41.9 & $\ldots$ & $\ldots$ & $\ldots$ & $\ldots$ \\
\hline PP97CA3 & 90.3 & 161.0 & 90.3 & 45.0 & $\ldots$ & $\ldots$ & $\ldots$ & $\ldots$ \\
\hline PP95CA5 & 90.5 & 160.7 & 90.5 & 46.0 & $\ldots$ & $\ldots$ & $\ldots$ & $\ldots$ \\
\hline PTT100 & $\ldots$ & $\ldots$ & $\ldots$ & $\ldots$ & 48.6 & 227.0 & 48.1 & 33.1 \\
\hline PTT95CB5 & $\ldots$ & $\ldots$ & $\ldots$ & $\ldots$ & 44.3 & 227.1 & 44.3 & 32.0 \\
\hline B100 & 78.7 & 160.7 & 65.9 & 42.5 & $\ldots$ & 226.1 & 12.6 & 34.6 \\
\hline B95gM5 & 79.5 & 160.5 & 67.0 & 45.4 & $\ldots$ & 225.9 & 12.0 & 34.7 \\
\hline B95E5 & 62.0 & 160.4 & 49.5 & 33.5 & $\ldots$ & 226.0 & 13.0 & 37.6 \\
\hline B90E10 & 61.2 & 160.2 & 48.0 & 34.3 & $\ldots$ & 225.9 & 12.8 & 39.1 \\
\hline N95CB5 & 68.0 & 161.0 & 62.0 & 42.0 & 6.6 & 226.7 & 12.0 & 34.7 \\
\hline N95CB2.5CA2.5 & 66.8 & 161.6 & 60.0 & 40.7 & $\ldots$ & 226.8 & 6.2 & 18.1 \\
\hline N90E5CB5 & 60.0 & 159.6 & 49.0 & 35.0 & $\ldots$ & 226.5 & 10.9 & 33.3 \\
\hline N85E10CB5 & 58.0 & 159.5 & 46.0 & 34.8 & $\ldots$ & 226.7 & 11.0 & 35.6 \\
\hline
\end{tabular}

phenomenon. Furthermore, no significant shift in melting peaks are observed on blending.

The addition of the compatibilizers, i.e. Elvaloy PTW and PP-g-MAH, to PP/PTT blend (B95E5, B90E10, B95gM5) entails considerable changes in the respective thermal characteristics, of which a reduction in crystallizability of the blend constituents is brought about, as evident from Table 2 data. This agrees with a similar published attempt [24]. The presence of the compatibilizer entities located at the interface results in a decrease of PTT dispersed phase domains which restricts the crystallization potential of both components. Further increase of Elvaloy PTW quantity (B90E10) has no detectable change on blend crystallization rate and degree possibly due to the interfacial saturation which is elaborated on for different blends in the literature [37]. It is interesting to note that PP-g-MAH influences PP thermal characteristics stronger than Elvaloy PTW, while an inverse trend is evident for PTT surmised to be on account of the structural similarity of the former pair and the higher reactivity of the latter one. Additionally, it is noteworthy that PTT cold crystallization disappears, however, the complex melting behavior of PP is preserved in presence of both compatibilizers revealing the influence of the compatibilizer entities on PP crystal morphology.

As for non-isothermal crystallization and melting, the compatibilizers decrease crystallization temperature of both components in blend. Neither complex melting nor cold crystallization is observed in melting scans after introducing compatibilizers.
Also, no significant shifts in melting peaks are observed on compatibilizer addition.

Nanoclay particles affect crystallization characteristics of the polymeric components (PP95CA5, PTT95CB5), where Cloisite 20A acts as nucleating agent and increases crystallization rate and degree of PP. Further addition of clay content has no favorable influence but a slightly negative impact is also observed which is ascribed to an increase in viscosity as well as chain folding energy $[38,39]$. Moreover, the complex melting behavior of PP is absent in the presence of nanoclay. As for PTT, Cloisite 30B particles contribute to the crystallization rate, however, crystallization degree slightly decreases. This may be related to the nucleating effect of nanoclays particles within PTT region leading to an increase in overall rate of crystal formation. Cold crystallization of PTT is also retained as evident from the respective melting scan.

Analogous to the above-stated findings, as regards the non-isothermal crystallization and melting thermograms, the introduction of nanoclays to the homopolymers increase crystallization temperature of PP and PTT. The favorable effect of nanoclays on PP crystallization has been addressed by Preschilla et al. [40]. Complex melting of PP is absent while cold crystallization is yet detectable for PTT in heating scans. Also, no significant shifts in melting peaks are observed on nanoclays addition.

Concerning the blend nanocomposite samples (N95CB5, N95CB2.5CA2.5, N90E5CB5, N85E10CB5), Cloisite 30B is effective as it increases PP crystallizability, whereas decreases that of PTT. 
On addition of Cloisite 20A to the nanocomposite sample, crystallization rate and degree of both PTT and PP are adversely altered. This may be associated with the tendency of Cloisite 20A to reside at the interfacial phase, rather than inside PTT domain which led to an increase in PTT droplets size and undermine the nucleating effect of PTT particles on PP crystallization. It should be noticed that the compatibilizer restricts crystallizability of the nanocomposite sample due to the same reasons stated earlier. This component diminishes the content of nanoclay particles in PTT phase and impairs both crystallization rate and degree. Further addition of the compatibilizer slightly affects crystallization and melting parameters which is believed to be due to the interfacial saturation and micelle formation. In respect of the heating scans, the complex melting behavior of PP is observed in the blend nanocomposite samples, while the cold crystallization of PTT is not.

Concerning non-isothermal mode, PTT crystallization temperature decreases while that of PP increases on introduction of Cloisite $30 \mathrm{~B}$ to the blend, whereas the addition of cloisite 20A has reducing effect on crystallization temperature of both components. The heating scan of the non-isothermally crystallized blend nanocomposites reveals neither complex melting behavior nor recrystallization phenomenon. Furthermore, no significant shift in melting peaks are discernible being consistent with the literature [26]. An overall comparison among the data on the samples crystallization behavior shows that the compatibilizer is remarkably more influential than nanoclay.

From kinetic standpoint, Avrami equation [41] has been employed whose characteristic parameters, that is to say, $n$ and $K$ are given in Table 4. $K$ denotes the rate constant and $n$ is the Avrami exponent which depends on the nucleation and growth mechanisms and is said to have contributions from growth dimensionality and nucleation mode [40]. According to the table, the $\mathrm{n}$ values mostly range between 2.2 and 3.6 which indicates athermal nucleation process followed by a two-dimensional (mostly in blend nanocomposites) or three-dimensional crystal growth, respectively. However, nanoclay particles alter the nucleation mode from athermal to thermal signified by a noticeable increase in the Avrami index. To describe the non-isothermal kinetics,
Table 4. Kinetic analysis data of the samples based on the Avrami equation

\begin{tabular}{|l|c|r|r|c|}
\hline \multicolumn{1}{|c|}{ Sample } & \multicolumn{2}{c|}{ Isothermal } & \multicolumn{2}{c|}{ Non-isothermal } \\
\hline & $\mathbf{n}$ & $\mathbf{l n} \mathbf{K}$ & $\mathbf{n}$ & $\mathbf{I n ~ K}$ \\
\hline PP100 & 2.3 & -5.16 & 4.5 & -19.98 \\
\hline PP97CA3 & 4.0 & -6.91 & 4.5 & -17.52 \\
\hline PP95CA5 & 5.3 & -10.17 & 4.9 & -18.77 \\
\hline B100 & 9.3 & -19.31 & 10.2 & -47.06 \\
\hline B95gM5 & 3.7 & -6.06 & 4.1 & -18.63 \\
\hline B95E5 & 2.3 & -5.17 & 4.8 & -20.06 \\
\hline B90E10 & 2.3 & -5.34 & 5.8 & -27.29 \\
\hline N95CB5 & 3.4 & -5.90 & 5.1 & -20.75 \\
\hline N95CA2.5CB2.5 & 3.5 & -6.14 & 4.0 & -16.53 \\
\hline N90E5CB5 & 2.2 & -4.90 & 4.7 & -20.83 \\
\hline N85E10CB5 & 2.5 & -5.78 & 4.4 & -18.83 \\
\hline
\end{tabular}

Avrami equation was modified by Wang and Run [25] by defining a reduced rate constant on the basis of the cooling rate. Non-isothermal kinetics with respect to $\mathrm{n}$ values shows that crystallization occurs via thermal mode through a three-dimensional growth.

\section{Conclusions}

The results from TEM on characterization of PP/ PTT blend nanocomposites show an inherent incompatibility which is resolved to some extent through compatibilizer incorporation. Cloisite 30B exhibits higher inclination to PTT phase rather PP. WAXS reveals an intercalated morphology where the gallery spacing is considerably contributed by Cloisite 30B. Also, introduction of nanoclays and compatibilizers has no detectable impact on PP $\alpha$-crystalline size. DSC studies indicate a simultaneous crystallization of both polymeric components in blends. Blending favors PP crystallizability, even though it curbs that of PTT. Addition of compatibilizers interferes with crystallizability of PP and PTT. However, nanoclays incorporation increases crystallizability of polymer in samples of polymer/ nanoclay. As to blend nanocomposites, the way the crystallization behavior varies relies on type of nanoclay. Based on Avrami kinetic analysis, nucleation stage of isothermal crystallization follows athermal mechanism, while that of non-isothermal obeys thermal mode. Furthermore, addition of nanoclays shifts nucleation mechanism from athermal to thermal mode. A comparison among the data on crystallization and melting characteristics shows that the compatibilizer is remarkably more influential than nanoclay. 


\section{Acknowledgements}

H.A. Khonakdar thanks Alexander von Humboldt foundation for financial support.

\section{References}

[1] Karian H.: Handbook of polypropylene and polypropylene composites. Marcel Dekker, New York (2003). DOI: $10.1201 / 9780203911808$

[2] Karger-Kocis J., Fakirov S.: Nano- and micromechanics of polymer blends and composites. Hanser, Munich (2009).

[3] Utracki L. A.: Polymer blends handbook. Kluwer, Dordrecht (2002).

[4] Karger-Kocsis J.: Polypropylene: Structure, blends and composites: Structure and morphology copolymers and blends composites. Chapman and Hall, London (1995).

[5] Dorscht B. M., Tzoganakis C.: Reactive extrusion of polypropylene with supercritical carbon dioxide: Free radical grafting of maleic anhydride. Journal of Applied Polymer Science, 87, 1116-1122 (2003). DOI: $10.1002 / a p p .11561$

[6] Kaci M., Benhamida A., Cimmino S., Silvestre C., Carfagna C.: Waste and virgin LDPE/PET blends compatibilized with an ethylene-butyl acrylate-glycidyl methacrylate (EBAGMA) terpolymer, 1. Macromolecular Materials and Engineering, 290, 987-995 (2005). DOI: 10.1002/mame.200500217

[7] Benhamida A., Kaci M., Cimmino S., Silvestre C., Duraccio D.: Melt mixing of ethylene/butyl acrylate/ glycidyl methacrylate terpolymers with LDPE and PET. Macromolecular Materials and Engineering, 294, 122-129 (2009).

DOI: $10.1002 /$ mame.200800214

[8] Asadinezhad A., Yavari A., Jafari S. H., Khonakdar H. A., Böhme F.: Description of the dynamic moduli of poly(trimethylene terephthalate)/polyamide- 12 blends in molten state. Polymer Engineering and Science, 45, 1401-1407 (2005).

DOI: $10.1002 /$ pen.20413

[9] Loyens W., Groeninckx G.: Rubber toughened semicrystalline PET: Influence of the matrix properties and test temperature. Polymer, 44, 123-136 (2003). DOI: 10.1016/S0032-3861(02)00743-7

[10] Pawlak A., Morawiec J., Pazzagli F., Pracella M., Galeski A.: Recycling of postconsumer poly(ethylene terephthalate) and high-density polyethylene by compatibilized blending. Journal of Applied Polymer Science, 86, 1473-1485 (2002).

DOI: 10.1002/app.11307

[11] Ray S. S., Bousmina M.: Compatibilization efficiency of organoclay in an immiscible polycarbonate/poly (methyl methacrylate) blend. Macromolecular Rapid Communications, 26, 450-455 (2005).

DOI: $10.1002 /$ marc. 200400586
[12] Li Y., Shimizu H.: Novel morphologies of poly(phenylene oxide) (PPO)/polyamide 6 (PA6) blend nanocomposites. Polymer, 45, 7381-7388 (2004).

DOI: $10.1016 /$ j.polymer.2004.09.018

[13] Khatua B. B., Lee D. J., Kim H. Y., Kim J. K.: Effect of organoclay platelets on morphology of nylon- 6 and poly(ethylene-ran-propylene) rubber blends. Macromolecules, 37, 2454-2459 (2004).

DOI: $10.1021 / \mathrm{ma} 0352072$

[14] Si M., Araki T., Ade H., Kilcoyne A. L. D., Fisher R., Sokolov J. C., Rafailovich M. H.: Compatibilizing bulk polymer blends by using organoclays. Macromolecules, 39, 4793-4801 (2006).

DOI: $10.1021 / \mathrm{ma} 060125+$

[15] Vo L. T., Giannelis E. P.: Compatibilizing poly(vinylidene fluoride)/nylon-6 blends with nanoclay. Macromolecules, 40, 8271-8276 (2007). DOI: $10.1021 / \mathrm{ma} 071508 \mathrm{q}$

[16] Goodarzi V., Jafari S. H., Khonakdar H. A., Monemian S. A., Hässler R., Jehnichen D.: Nonisothermal crystallization kinetics and determination of surface-folding free energy of PP/EVA/OMMT nanocomposites. Journal of Polymer Science Part B: Polymer Physics, 47, 674-684 (2009).

DOI: $10.1002 /$ polb. 21672

[17] Huang J. J., Keskkula H., Paul D. R.: Rubber toughening of an amorphous polyamide by functionalized SEBS copolymers: Morphology and Izod impact behavior. Polymer, 45, 4203-4215 (2004).

DOI: $10.1016 /$ j.polymer.2004.04.002

[18] Li W., Karger-Kocsis J., Thomann R.: Compatibilization effect of $\mathrm{TiO}_{2}$ nanoparticles on the phase structure of $\mathrm{PET} / \mathrm{PP} / \mathrm{TiO}_{2}$ nanocomposites. Journal of Polymer Science Part B: Polymer Physics, 47, 1616-1624 (2009). DOI: $10.1002 /$ polb.21752

[19] Robeson L. M.: Polymer blends: A comprehensive review. Hanser, Munich (2007).

[20] Mittal V.: Optimization of polymer nanocomposite properties. Wiley-VCH, Weinheim (2010).

[21] Schultiz J. M.: Polymer crystallization: The development of crystalline order in thermoplastic polymers. American Chemical Society, Washington (2001).

[22] Jafari S. H., Khonakdar H. A., Asadinezhad A.: A review on homopolymer, blends, and nanocomposites of poly (trimethylene terephthalate) as a new addition to the aromatic polyesters class. Iranian Polymer Journal, 17, 19-38 (2008).

[23] Xue M-L., Yu Y-L., Chuah H. H.: Reactive compatibilization of poly(trimethylene terephthalate)/polypropylene blends by polypropylene-graft-maleic anhydride. Part 2. Crystallization behavior. Journal of Macromolecular Science Part B: Physics, 46, 603-615 (2007). DOI: $10.1080 / 00222340701258008$

[24] Lin S-W., Cheng Y-Y.: Miscibility, mechanical and thermal properties of melt-mixed poly(trimethylene terephthalate)/polypropylene blends. Polymer-Plastics Technology and Engineering, 48, 827-833 (2009). DOI: $10.1080 / 03602550902994888$ 
[25] Wang Y., Run M.: Non-isothermal crystallization kinetic and compatibility of PTT/PP blends by using maleic anhydride grafted polypropylene as compatibilizer. Journal of Polymer Research, 16, 725-737 (2009). DOI: 10.1007/s10965-009-9279-6

[26] Upadhyay D., Mohanty S., Nayak S. K., Parvaiz M. R., Panda B. P.: Impact modification of poly(trimethylene terephthalate)/polypropylene blend nanocomposites: Fabrication and characterization. Journal of Applied Polymer Science, 120, 932-943 (2011).

DOI: $10.1002 / a p p .33106$

[27] Pegoretti A., Dorigato A., Brugnara M., Penati A.: Contact angle measurements as a tool to investigate the filler-matrix interactions in polyurethane-clay nanocomposites from blocked prepolymer. European Polymer Journal, 44, 1662-1672 (2009).

DOI: $10.1016 /$ j.eurpolymj.2008.04.011

[28] Hári J., Dominkovics Z., Fekete E., Pukánszky B.: Kinetics of structure formation in PP/layered silicate nanocomposite. Express Polymer Letters, 3, 684-691 (2009).

DOI: $10.3144 /$ expresspolymlett.2009.87

[29] Varga J.: Polypropylene structure, blends and composites. Chapman and Hall, London (1995).

[30] Favaro M. M., Branciforti M. C., Bretas R. E. S.: Influence of a terpolymer compatibilizer on the nanostructure of poly(trimethylene terephthalate)/montmorillonite nanocomposites. Polymers for Advanced Technologies, 20, 940-949 (2009).

DOI: $10.1002 /$ pat.1343

[31] Martín Z., Jiménez I., Gómez-Fantous M. A., West M., Hitchcock A. P.: Interfacial interactions in polypropylene-organoclay-elastomer nanocomposites: Influence of polar modifications on the location of the clay. Macromolecules, 44, 2179-2189 (2011).

DOI: $10.1021 / \mathrm{ma1} 102707 \mathrm{f}$

[32] Bordes P., Pollet E., Bourbigot S., Avérous L.: Structure and properties of PHA/clay nano-biocomposites prepared by melt intercalation. Macromolecular Chemistry and Physics, 209, 1473-1484 (2008). DOI: $10.1002 /$ macp. 200800022
[33] Alexander, L. E.: X-ray diffraction methods in polymer science. Wiley, New York (1969).

[34] Zipper P., Jánosi A., Wrentschur E.: Scanning X-ray scattering of mouldings from semicrystalline polymers. Journal de Physique IV, 3, 33-36 (1993).

DOI: $10.1051 / j p 4: 1993807$

[35] Medellín-Rodríguez F. J., Mata-Padilla M., SánchezValdes S., Vega-Díaz S., Dávalos-Montoya O.: Steplike melting mechanisms of isothermally crystallized isotactic polypropylene. Journal of Polymer Science Part B: Polymer Physics, 46, 2188-2200 (2008). DOI: $10.1002 /$ polb.21551

[36] Asadinezhad A., Jafari S. H., Khonakdar H. A., Böhme F., Hässler R., Häussler L.: Kinetics of isothermal crystallization and subsequent melting behavior of PTT/ PA12 blend. Journal of Applied Polymer Science, 106, 1964-1971 (2007).

DOI: $10.1002 / a p p .26808$

[37] Tao Y., Mai K.: Non-isothermal crystallization and melting behavior of compatibilized polypropylene/recycled poly(ethylene terephthalate) blends. European Polymer Journal, 43, 3538-3549 (2007). DOI: $10.1016 /$ j.eurpolymj.2007.05.007

[38] Aravind I., Albert P., Ranganathaiah C., Kurian J. V., Thomas S.: Compatibilizing effect of EPM-g-MA in EPDM/poly(trimethylene terephthalate) incompatible blends. Polymer, 45, 4925-4937 (2004).

DOI: 10.1016/j.polymer.2004.04.063

[39] Li Y., Wang S., Zhang Y., Zhang Y.: Crystallization behavior of carbon black-filled polypropylene and polypropylene/epoxy composites. Journal of Applied Polymer Science, 102, 104-118 (2006).

DOI: 10.1002 app.23254

[40] Preschilla N., Abdul Rasheed A. S., Sahadevan S., Biswas A., Bellare J. R., Shyamroy S.: Study of layered silicate clays as synergistic nucleating agent for polypropylene. Journal of Polymer Science Part B: Polymer Physics, 48, 1786-1794 (2010).

DOI: $10.1002 /$ polb.22044

[41] Jena A. K., Chaturvedi M. C.: Phase transformations in materials. Prentice Hall, New Jersey (1992). 